\title{
On Triangular Secure Domination Number
}

\author{
Emily L. Casinillo*, Leomarich F. Casinillo, Jorge S. Valenzona and Divina L. Valenzona \\ Department of Mathematics and Physics \\ Visayas State University \\ Visca, Baybay City, Leyte, Philippines \\ *Correspondence: elagumbay12201990@gmail.com
}

\begin{abstract}
Let $T_{m}=\left(V\left(T_{m}\right), E\left(T_{m}\right)\right)$ be a triangular grid graph of $m \in \mathbb{N}$ level. The order of graph $T_{m}$ is called a triangular number. A subset $T$ of $V\left(T_{m}\right)$ is a dominating set of $T_{m}$ if for all $u \in V\left(T_{m}\right) \backslash T$, there exists $v \in T$ such that $u v \in E\left(T_{m}\right)$, that is, $N[T]=V\left(T_{m}\right)$. A dominating set $T$ of $V\left(T_{m}\right)$ is a secure dominating set of $T_{m}$ if for each $u \in V\left(T_{m}\right) \backslash T$, there exists $v \in T$ such that $u v \in E\left(T_{m}\right)$ and the set $(T \backslash\{u\}) \cup\{v\}$ is a dominating set of $T_{m}$. The minimum cardinality of a secure dominating set of $T_{m}$, denoted by $\gamma_{s}\left(T_{m}\right)$ is called a secure domination number of graph $T_{m}$. A secure dominating number $\gamma_{s}\left(T_{m}\right)$ of graph $T_{m}$ is a triangular secure domination number if $\gamma_{s}\left(T_{m}\right)$ is a triangular number. In this paper, a combinatorial formula for triangular secure domination number of graph $T_{m}$ was constructed. Furthermore, the said number was evaluated in relation to perfect numbers.
\end{abstract}

Keywords: triangular secure domination number; Mersenne prime; perfect number.

2010 Mathematics Subject Classification: 05C69.

\begin{abstract}
Abstrak
Misal $T_{m}=\left(V\left(T_{m}\right), E\left(T_{m}\right)\right)$ adalah graf triangular grid ingkat $m \in \mathbb{N}$. Order dari graf $T_{m}$ disebut bilangan triangular. Suatu himpunan bagian $T$ dari $V\left(T_{m}\right)$ adalah himpunan yang mendominasi $T_{m}$ jika untuk semua $u \in V\left(T_{m}\right) \backslash T$ terdapat $v \in T$ sehingga $u v \in E\left(T_{m}\right)$, yaitu, $N[T]=V\left(T_{m}\right)$. Suatu himpunan $T$ yang mendominasi $V\left(T_{m}\right)$ adalah himpunan mendominasi aman dari $T_{m}$ jika untuk setiap $u \in V\left(T_{m}\right) \backslash T$ terdapat $v \in T$ sehingga $u v \in E\left(T_{m}\right)$ dan himpunan $(T \backslash\{u\}) \cup\{v\}$ adalah himpunan yang mendominasi $T_{m}$. Kardinalitas minimum dari suatu himpunan mendominasi aman dari $T_{m}$, dinotasikan dengan $\gamma_{s}\left(T_{m}\right)$, bilangan dominasi aman dari graf $T_{m}$. Suatu bilangan dominasi aman $\gamma_{s}\left(T_{m}\right)$ dari graf $T_{m}$ adalah bilangan dominasi aman tringular jika $\gamma_{s}\left(T_{m}\right)$ adalah bilangan triangular. Dalam paper ini dikonstruksi suatu formula kombinatorial untuk bilangan dominasi aman triangular dari suatu graf $T_{m}$. Lebih lanjut, bilangan tersebut dievaluasi hubungannya dengan bilangan sempurna. Kata kunci:.bilangan dominasi aman triangular; prim Mersenne; bilangan sempurna
\end{abstract}




\section{INTRODUCTION}

Consider a connected graph $G=(V(G), E(G))$ and let $u \in V(G)$. The neighborhood of $u$ is the set $N_{G}(u)=N(u)=\{v \in V(G): u v \in E(G)\}$. If $A \subseteq V(G)$, then the open neighborbood of $A$ is the set $N_{G}(A)=N(A)=\bigcup_{u \in A} N_{G}(u)$. The closed neighborhood of $A$ is denoted and defined by $N_{G}[A]=$ $N[A]=A \cup N(A)$. For other concepts in graph theory, readers may refer to [1] [2] [3]. A subset $T$ of $V(G)$ is a minimum dominating set in graph $G$ if for every $u \in V(G) \backslash T$, there exists $v \in T$ such that $u v \in E(G)$, that is, $N[T]=V(G)$. The smallest cardinality of a dominating set $T$ is called dominating number of graph $G$ denoted by $\gamma(G)$. Domination concepts in graphs and some of its variants can be found in [4] [5] [6] [7] [8]. A vertex $x \in T$ is said to $T$-defend $u$, where $u \in V(G) \backslash T$, if $x u \in E(G)$ and $(T \backslash\{x\}) \cup\{u\}$ is a dominating set in $G$. A dominating set $T$ is a secure dominating set if for every $u \in V(G) \backslash T$, there exists $v \in T$ such that $v T$-defends $u$. The rigorous concepts of secure domination number of graphs had been studied in [9] [10] [11] [12]. Let $T_{m}=\left(V\left(T_{m}\right), E\left(T_{m}\right)\right)$ be a triangular grid graph where $m \in \mathbb{N}$. A graph $T_{m}$ is a sub graph of a tiling of the plane with equilateral triangles defined by the finite number of triangles called cells. The order of graph $T_{m}$ is a triangular number, that is, $\left|T_{m}\right|=$ $\frac{m(m+1)}{2}$, where $m$ is the $m^{\text {th }}$ triangular number in graph $T_{m}$ [13] [2] [14]. Figure 1 below shows the illustration of triangular grid graphs $T_{4}$ and $T_{5}$.
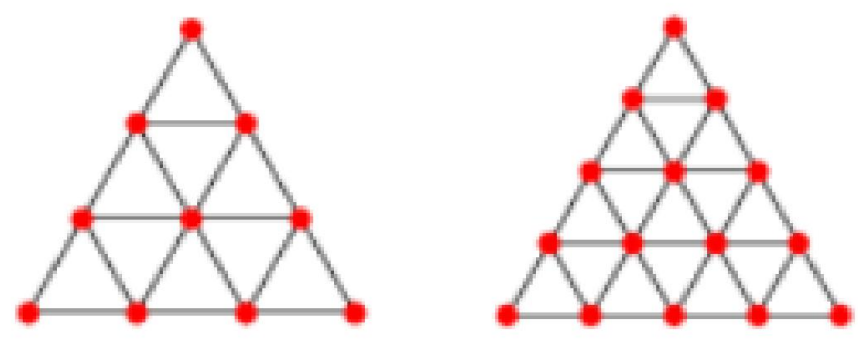

Figure 1. Triangular grid graphs $T_{4}$ and $T_{5}$, respectively.

The minimum cardinality of a secure dominating set of $T_{m}$, denoted by $\gamma_{s}\left(T_{m}\right)$ is called a secure domination number of $T_{m}$. A secure dominating number $|T|=\gamma_{s}\left(T_{m}\right)$ of graph $T_{m}$ is a triangular secure domination number if $\gamma_{s}\left(T_{m}\right)$ is a triangular number. In number theory, Mersenne primes are type of prime numbers that can be derived using the formula $M_{p}=2^{p}-1$, where $p$ is a prime number. Also, a perfect number is a positive integer of the form $P(p)=2^{p-1}\left(2^{p}-1\right)$, where $p$ is prime and $2^{p}-1$ is a Mersenne prime. Further, a perfect number can be written as the sum of its proper positive divisors, i.e., a number that is half the sum of all of its positive divisors. Let $n$ be a positive integer and $\sigma(n)$ be the sum of all the positive divisors of $n$. So, we have $\sigma(n)=\sum_{d \mid n} d$, where $d$ is a positive divisor of $n$. Hence, we say that $n$ is a perfect number if $\sigma(n)=2 n$ by definition of perfect number [15] [16]. In this paper, we developed a combinatorial formula that determines the triangular secure domination number of triangular grid graph $T_{m}$. Furthermore, triangular secure domination number was investigated in relation to the intriguing numbers namely: Mersenne prime and perfect number. 


\section{RESULTS}

The following Remark 2.1 is immediate from the definition of secure domination number of path $P_{n}$, where $n$ is a positive integer.

Remark 2.1. [10] Let $G=P_{n}$ be a path of order $n \in \mathbb{N}$. Then,

$$
\gamma_{s}(G)= \begin{cases}\frac{n+1}{2} & \text { if } n \equiv 1(\bmod 2) \\ \frac{n}{2} & \text { if } n \equiv 0(\bmod 2)\end{cases}
$$

The next Theorem 2.2 is a direct consequence from Remark 2.1. The Theorem determines the secure domination number of graph $T_{m}$ where $m$ is an odd positive integer which denotes as the level of graph. The Theorem concludes that the secure domination number of graph $T_{m}$ is the $\left(\frac{m+1}{2}\right)^{t h}$ triangular number.

Theorem 2.2. Let $T_{m}$ be a triangular grid graph of level $m \in \mathbb{N}$. If $m \equiv 1(\bmod 2)$, then $\gamma_{s}\left(T_{m}\right)=$

$$
\frac{1}{8}\left(m^{2}+4 m+3\right) \text { and } \gamma_{s}\left(T_{m}\right) \text { is the }\left(\frac{m+1}{2}\right)^{t h} \text { triangular number. }
$$

Proof: Suppose that $T_{m}$ is a triangular grid graph and $m \equiv 1(\bmod 2)$, then the Theorem will be proven with the following two cases:

Case 1: If $m=1$, then $\gamma_{s}\left(T_{m}\right)=1$ and obviously the hypothesis holds.

Case 2: Let $m \geq 3$. Now, consider the odd slanting paths of graph $T_{m}$, that is a sequence of paths $\left\{P_{n}\right\}$ where $n \in\{1,3, \ldots, m\}$. By Remark 2.1, we obtained the series of secure domination number of odd slanting paths of graph $T_{m}$ as follows:

$$
\sum_{n=1}^{m} \gamma_{s}\left(P_{n}\right)=\sum_{i=1}^{\frac{m+1}{2}}\left[\frac{n+1}{2}\right]=\sum_{i=1}^{\frac{m+1}{2}} i=\frac{\left(\frac{m+1}{2}\right)\left(\frac{m+1}{2}+1\right)}{2}=\frac{1}{8}\left(m^{2}+4 m+3\right) \text {. }
$$

Since every vertex $v$ in an even slanting paths is dominated by the one of the dominating vertex in an odd slanting paths, that is, $\forall v \in V\left(P_{n+1}\right) \subset V\left(T_{m}\right) \backslash T$, there exist $x \in V\left(P_{n}\right) \subset T$ such that $v x \in$ $E\left(T_{m}\right)$, then $T$ is a dominating set in graph $T_{m}$. Furthermore, any vertex $y \in T$ is a secure dominating vertex since for all $w \in V\left(T_{m}\right) \backslash T, w y \in E\left(T_{m}\right)$, and $(T \backslash\{y\}) \cup\{w\}$ is dominating set in graph $T_{m}$. Hence, it is concluded that $\gamma_{s}\left(T_{m}\right)=\frac{1}{8}\left(m^{2}+4 m+3\right)$ and it is the $\left(\frac{m+1}{2}\right)^{\text {th }}$ triangular number. This completes the proof.

Next result is a Corollary which is immediate from Theorem 2.2. This Corollary will determine the secure domination number of graph $T_{m}$ where $m$ is an even positive integer.

Corollary 2.3. Let $T_{m}$ be a triangular grid graph of level $\mathrm{m} \in \mathbb{N}$. If $m \equiv 0(\bmod 2)$, then $\gamma_{s}\left(T_{m}\right)=$ $\gamma_{s}\left(T_{m-1}\right)+\gamma\left(P_{m}\right)$

Proof: It is clear that the first $(m-1)$ levels of graph $T_{m}$ has $\gamma_{s}\left(T_{m-1}\right)$ secure domination number by Theorem 2.2. This configuration already dominates the whole graph $T_{m}$, that is, for all $u \in$ 
$T, N[T]=V\left(T_{m}\right)$. But this dominating set is not a secure domination. So, it follows that to make it a secure dominating set, we will have an additional dominating vertex for $m^{\text {th }}$ level of graph $T_{m}$, that is, $\gamma\left(P_{m}\right)$. Hence, $\gamma_{s}\left(T_{m}\right)=\gamma_{s}\left(T_{m-1}\right)+\gamma\left(P_{m}\right)$. This completes the proof.

The following Remark 2.4 shows the domination number of path $P_{m}$ of order $m \geq 1$, while Remark 2.5 shows the value of $\gamma_{s}\left(T_{m}\right)$ where $m \equiv 0(\bmod 2)$, which are immediate results from Corollary 2.3 and Remark 2.4.

Remark 2.4. [7] Let $P_{m}$ be a path of order $\mathrm{m} \geq 1$. Then, $\gamma\left(P_{m}\right)=\left\lceil\frac{m}{3}\right\rceil$.

Remark 2.5. Let $T_{m}$ be a triangular grid graph of level $m \in \mathbb{N}$. If $m \equiv 0(\bmod 2)$, then $\gamma_{s}\left(T_{m}\right)=$ $\frac{1}{8}\left(m^{2}+2 m\right)+\left\lceil\frac{m}{3}\right\rceil$.

The following Theorem and Corollary below are direct consequences of definition of perfect number and Theorem 2.2.

Theorem 2.6. Let $\frac{m+1}{2}=2^{t}-1$, where $m \equiv 1(\bmod 2)$ is the level of triangular grid graph $T_{m}$ and $t \in \mathbb{N}$. Then, $\frac{m+1}{2}$ is a prime number for some prime number $t$ if and only if $\gamma_{s}\left(T_{m}\right)$ is a perfect number.

\section{Proof:}

$(\Longrightarrow)$ Suppose that $\frac{m+1}{2}=2^{t}-1$, where $t$ is a prime number and $m \equiv 1(\bmod 2)$. By Theorem 2.2, it directly follows that

$$
\gamma_{s}\left(T_{m}\right)=\frac{1}{8}\left(m^{2}+4 m+3\right)=\frac{\left(\frac{m+1}{2}\right)\left(\frac{m+1}{2}+1\right)}{2}=2^{t-1}\left(2^{t}-1\right) .
$$

Since $\frac{m+1}{2}$ is a prime number for some prime $t$, then, we have $\sigma\left(\frac{m+1}{2}\right)=\sigma\left(2^{t}-1\right)=2^{t}$. So it follows that $\sigma\left(\gamma_{s}\left(T_{m}\right)\right)=2^{t}\left(2^{t}-1\right)=2 \gamma_{s}\left(T_{m}\right)$ and follows directly that $\gamma_{s}\left(T_{m}\right)$ is a perfect number.

$(\Leftarrow)$ For the converse, we let $\gamma_{s}\left(T_{m}\right)$ be a perfect number and $\frac{m+1}{2}=2^{t}-1$. By Theorem 2.2, we have $\gamma_{s}\left(T_{m}\right)=2^{t-1}\left(2^{t}-1\right)$. Since the greatest common divisor of $2^{t-1}$ and $\left(2^{t}-1\right)$ is 1 , then $\sigma\left(\gamma_{s}\left(T_{m}\right)\right)=\sigma\left(2^{t-1}\right) \sigma\left(2^{t}-1\right)=\left(2^{t}-1\right) \sigma\left(2^{t}-1\right)$. By the definition of perfect number, we have, $\left(2^{t}-1\right) \sigma\left(2^{t}-1\right)=2^{t}\left(2^{t}-1\right)$ and it simply follows that $\sigma\left(2^{t}-1\right)=2^{t}$. Thus, it clearly follows that $2^{t}-1$ is a Mersenne prime number for some prime $t$ and this completes the proof.

Corollary 2.7. Let $T_{m}$ be a triangular grid graph of level $m \in \mathbb{N}$. Then $\gamma_{s}\left(T_{m}\right)+\gamma_{s}\left(T_{m-2}\right)=$ $\left[\gamma_{s}\left(T_{m}\right)-\gamma_{s}\left(T_{m-2}\right)\right]^{2}$.

Let $V_{2}, V_{4}$ and $V_{6}$ be sets of vertices of triangular grid graph $T_{m}$ having the degree of 2,4 and 6 , respectively, that is, $V\left(T_{m}\right)=V_{2} \cup V_{4} \cup V_{6}$ and $V_{2} \cap V_{4} \cap V_{6}=\emptyset$. Then, the following Lemma is constructed. 
Lemma 2.8. For any triangular grid graph $T_{m}$ where $m \in \mathbb{N}$, the following statements hold:

$$
\begin{array}{ll}
\text { i. }\left|V_{2}\right|=3 & \text { if } m \geq 2 \text {; } \\
\text { ii. }\left|V_{4}\right|=3 m-6 & \text { if } m \geq 3 \text {; and } \\
\text { iii. }\left|V_{6}\right|=\frac{1}{2}\left(m^{2}-5 m+6\right) & \text { if } m \geq 4 .
\end{array}
$$

Proof: By counting the vertices of triangular grid graph $T_{m}$ in relation to the sets $V_{2}, V_{4}$ and $V_{6}$, then, it is clear that Lemma 2.8 holds.

The next corollary which is immediate from Lemma 2.8, shows the relationships of sets $V_{2}, V_{4}$ and $V_{6}$ in relation to the interval values of positive integer $m$.

Corollary 2.9. Let $T_{m}$ be a triangular grid graph with order $m \in \mathbb{N}$. Then the following holds:
i. $\left|V_{6}\right|<\left|V_{2}\right|=3 \leq\left|V_{4}\right| \quad$ if $m=3$ or 4 ;
ii. $3=\left|V_{2}\right| \leq\left|V_{6}\right| \leq\left|V_{4}\right| \quad$ if $5 \leq m \leq 9$; and
iii. $3=\left|V_{2}\right|<\left|V_{4}\right|<\left|V_{6}\right| \quad$ if $m \geq 10$.

Next, the following result is quick from Remark 2.1, Theorem 2.2 and Lemma 2.8, shwoing the number of dominating vertices of graph $T_{m}$ in the sets $V_{2}, V_{4}$ and $V_{6}$.

Theorem 2.10. Suppose that $T_{m}$ be a triangular grid graph with order $m \equiv 1(\bmod 2)$ and $T \subset$ $V\left(T_{m}\right)$ be the set of triangular secure dominating vertices. Then the following holds:
i. $\left|V_{2} \cap T\right|=3$
if $m \geq 3$;
ii. $\left|V_{4} \cap T\right|=\frac{1}{2}(3 m-9)$
if $m \geq 5$; and
iii. $\left|V_{6} \cap T\right|=\frac{1}{8}\left(m^{2}-8 m+15\right)$
if $m \geq 7$.

Proof: By Remark 2.1 and Theorem 2.2, it is clear that $V_{2} \subseteq T$. So, it follows that $\left|V_{2} \cap T\right|=3$ by Lemma 2.8, thus (i) holds. Same argument can be applied to (ii) and (iii). And this completes the proof.

\section{CONCLUSIONS}

In this study, we developed a combinatorial formula to determine the triangular secure domination number of graph $T_{m}$, that is, $\gamma_{s}\left(T_{m}\right)=\frac{1}{8}\left(m^{2}+4 m+3\right)$ where $m$ is odd. Result reveals that $\gamma_{s}\left(T_{m}\right)$ is the $\left(\frac{m+1}{2}\right)^{t h}$ triangular number for $m \equiv 1(\bmod 2)$. Also, it is concluded that $\gamma_{s}\left(T_{m}\right)$ can be characterized with the concept of perfect numbers, that is, by considering $\frac{m+1}{2}=2^{t}-1$, where

$m \equiv 1(\bmod 2)$ is the level of triangular grid graph $T_{m}$ and $t \in \mathbb{N}$. So, we have $\frac{m+1}{2}$ is a Mersenne prime number for some prime number $t$ if and only if $\gamma_{s}\left(T_{m}\right)$ is a perfect number. Futhermore, we have generated some important results regarding the triangular secure domination number of graph $T_{m}$ where $m \equiv 1(\bmod 2)$. 


\section{ACKNOWLEDGEMENT}

We would like to acknowledge the referees for the rigorous review and comments for the improvement of this paper.

\section{REFERENCES}

[1] S. R. Canoy Jr. and I. J. L. Garces, "Convex sets under some graph operations," Graphs and Combinatorics, vol. 18, pp. 787-793, 2002.

[2] G. Chartrand and P. Zhang, A First Course in Graph Theory, New York: Dover Publication Inc., 2012.

[3] O. Ore, Theory of Graphs, American Mathematical Society Provedence: R. I., 1962.

[4] L. F. Casinillo, "A note on Fibonacci and Lucas number of domination in path," Electronic Journal of Graph Theory and Applications, vol. 6, no. 2, pp. 317-325, 2018.

[5] L. F. Casinillo, E. T. Lagumbay and H. R. F. Abad, "(2017). A note on connected interior domination in join and corona of two graphs," IOSR Journal of Mathematics, vol. 13, no. 2, pp. 6669, 2017.

[6] E. J. Cockayne and S. T. Hedetniemi, "Towards a theory of domination in graph," Networks Advanced Topics, vol. 7, pp. 247-261, 1977.

[7] T. W. Haynes, S. T. Hedetniemi and P. J. Slater, Fundamentals of Domination in Graphs, New York: Marcel Dekker, 1998.

[8] J. M. Tarr, Domination in graphs, Graduate Theses and Dissertations: Retrieved from https://scholarcommons.usf.edu/etd/1786, 2010.

[9] E. C. Castillano, R. A. L. Ugbinada and S. R. Canoy Jr., "Secure domination in the joins of graphs," Applied Mathematical Sciences, vol. 8, no. 105, pp. 5203-5211, 2014.

[10] E. J. Cockayne, "Irredundance, secure domination and maximum degree in trees," Discrete Mathematics, vol. 307, pp. 12-17, 2007.

[11] E. L. Enriquez, "Secure convex dominating sets in corona of graphs," Applied Mathematical Sciences, vol. 9, no. 1, pp. 5961-5967, 2015.

[12] E. L. Enriquez, "Secure restrained domination in join and corona of graphs," Global Journal of Pure and Applied Mathematics, vol. 12, no. 1, pp. 507-516, 2016.

[13] L. F. Casinillo, "Odd and even repetition sequences of independent domination number," Notes on Number Theory and Discrete Mathematics, vol. 26, no. 1, pp. 8-20, 2020.

[14] M. Dorfling and M. A. Henning, "A note on power domination in grid graphs," Discrete Applied Mathematics, vol. 154, pp. 1023-1027, 2006.

[15] L. F. Casinillo, "Some new notes on Mersenne primes and perfect numbers," Indonesian Journal of Mathematics Education, vol. 3, no. 1, pp. 15-22, 2020.

[16] T. Muche, M. T. G. Lemma and A. Atena, "Perfect if and only if triangular," Advances in Theoretical and Applied Mathematics, vol. 12, no. 1, pp. 39-50, 2017. 